\title{
ЛИНГВИСТИЧЕСКИЙ ПОВОРОТ И ЕГО ЗНАЧЕНИЕ ДЛЯ АНАЛИТИЧЕСКОЙ ФИЛОСОФИИ
}

\author{
Л.В. Кулабухова
}

Высказывания философии не факту-
альны, а лингвистичны по характе-
ру. То есть они не описывают по-
ведение физических или ментальных
объектов; они выражают определе-
ния или формальные последователь-
ности определений. А.Дж. Айер

Современная аналитическая философия с момента своего возникновения эксплицитно противопоставила себя предшествующей философской традиции и выдвинула программу трансформации философии в науку - дисциплину, в которой для проверки философских утверждений использовались бы универсально признанные процедуры принятия решений. Развитие логики на новом этапе заставило под иным углом зрения посмотреть и на решение философских проблем, рассматривая их через призму языка. Аналитические философы попытались подвергнуть анализу сами формулировки философской мысли и тем самым прояснить ее логическую истинность или несостоятельность. Новый метод исследования языка в аналитической философии призван был послужить основой для достижения консенсуса с целью прекращения бесконечных споров философов над одними и теми же вопросами, предложив конкретные механизмы достижения обоснованного знания. Этот метод по-разному рассматривался и истолковывался аналитическими философами: как прояснение выдвигаемых

Актуальні проблеми духовності

(Відп. ред.: Я.В. Шрамко)

Кривий Ріг (2006), 155-164 
положений, анализ логической формы, уточнение логического синтаксиса и др.

Цель данной статьи состоит в том, чтобы рассмотреть проблемы инновационного направления в аналитической философии ХХ века лингвистического поворота, согласно которому философские вопросы решаются либо посредством реформирования языка, либо более точным истолкованием языковых выражений.

Аналитическая философия возникла во второй половине XIX века в Австрии и Германии, а в XX веке она заняла доминирующее положение в академической философии англоязычных стран и во многих странах континентальной Европы. Приверженцы лингвистического поворота в аналитической философии не образуют единой философской школы, здесь, скорее всего можно выделить два основных направления, которые и ведут между собой дискуссии, предлагая различные подходы к решению философских вопросов.

1. Лингвистические философы, которые в качестве наиболее подходящего средства для решения философских проблем рассматривают анализ обычного языка.

2. Лингвистические философы, которые считают, что обыденный язык неадекватен для решения философских вопросов и предлагают создать для этих целей некий идеальный язык.

Представители аналитической философии, такие как Р.Карнап, Г.Бергман, Дж. Виздом и Г. Райл, некоторые работы которых будут рассмотрены в данной статье, по существу пытались ответить на два основных вопроса:

1. Какова природа философии и какие методы философствования должны приниматься в качестве наиболее адекватных?

2. Возможно ли достичь заметного прогресса на путях анализа языка науки и философии?

Сам термин «лингвистический поворот», хотя и был впервые употреблен Г.Бергманом, но обоснован и расширен Ричардом Рорти в одноименной книге, в которой он как редактор собрал труды философов, посвященные лингвистическому повороту, а также дал развернутую критическую оценку этому явлению в аналитической философии в своем предисловии к данной книге. 
Для Бергмана философия представляет своего рода лингвистическую рекомендацию: «Все лингвистические философы говорят о мире, имея в виду язык. Это и есть лингвистический поворот, фундаментальный первый шаг, метод, с которым согласны философы идеального и обычного языка. Доводы лингвистических философов - это практические доводы, предлагающие традиционным философам: попытайтесь сделать так-то и так-то и увидите, что вы достигните больших результатов» (Цит. по: [7, с. 8].

Тем не менее, противники лингвистического поворота подвергали критике этот метод философствования, рассматривая его как своего рода хождение по замкнутому кругу, поскольку, на их взгляд, в результате применения лингвистического метода анализируются только слова, а не идеи и универсалии, которые эти слова обозначают.

Несмотря на имеющееся согласие по вопросу о важности языка для анализа философских высказываний и научных положений, между самими представителями данного направления не существует единого мнения, какой же язык должен использоваться лингвистическими философами. Можно утверждать, что существуют приверженцы «обычного языка» и «идеального языка». Предложенная альтернатива обыденному языку может оказаться достаточно эффективной и полезной также как и демонстрация неправильного использования языка.

Бергман и Стросон считают, что философия должна выработать особый язык, который не используется в обычной речи, т.е. идеальный язык, функция которого должна состоять в разъяснении сложных философских проблем. Другие лингвистические философы, такие как Максвелл и Фейгл считают, что идеальный язык, хотя возможен логически, не возможен прагматически и утверждают, что обыденный язык - это и есть язык, идеально подходящий для разрешения философских вопросов, только использование его обычным человеком и философом должно осуществляться на разных уровнях. Согласно этой точке зрения, необходимость в идеальном языке отпадает сама по себе.

Примиряя эти два направления, можно отметить, что вместо проведения контрастов между идеальным и обычным языком, «историкограмматическим синтаксисом» и «логико-грамматической формой», имеет смысл просто провести границу между обычным (повседневным) и особым, философским использованием языка. Придерживаясь этой точки зрения, можно принять положение, что философские проблемы не открываются подобно законам физики, а создаются, и если мы их создаем, то должны объяснить, зачем они нам нужны, и обосновать их. 
Лингвистический поворот является своего рода реакцией на определение философии как дисциплины, пытающейся решить традиционные проблемы, порожденные точкой зрения здравого смысла. Как замечает Бэнджемин Уорф, «Мы должны признать влияние языка на различные виды деятельности людей не столько в особых случаях его употребления, сколько в его постоянно действующих общих законах и в повседневной оценке им тех или иных явлений» $[1$, с. 185].

С самого своего возникновения в аналитической философии довольно четко обозначились два основные течения:

1. Исследования, существенным образом учитывавшие достижения символической логики (Больцано, Фреге, Рассел).

2. Направление, ориентированное на анализ обычного языка (Мур, поздний Витгенштейн, Остин и др.).

Еще в 1905 г. Мур упоминал об «анализе философских идей», а в труде «Наше знание о внешнем мире» в 1914 г. Рассел ведет речь о «логико-аналитическом методе». Ф. Вайсман в статье довоенного журнала «Erkenntnis» пишет, что «философию можно назвать логическим анализом наших мыслей» [9, с. 266]. Согласно ему, этот анализ состоит из «разложения мысли на логические элементы, как фармацевт исследует вещества» [9, с.266]. Существует точка зрения, что аналитическая философия началась с Рассела (логическая ветвь) и Мура (философия обыденного языка) и что ее рождение может быть датировано 1903-м годом - время одновременных публикаций «Принципов математики» Рассела и «Опровержения идеализма» Мура. Однако можно утверждать, что это произошло на 20 лет раньше в работах Фреге, поскольку как Рассел, так и Мур ссылаются на то, что всем вопросам логического анализа они обязаны Фреге.

Аналитическую философию отмечает чрезвычайное многообразие. Она охватывает почти все традиционные разделы, такие как онтология, философия языка, этика, философия религии и др. Некоторые философы считают, что такое множество подходов дает повод усомниться в том, что это движение образует единое направление, но, с другой стороны, это может быть и его сильной стороной, что позволяет аналитической философии исследовать не только разные сферы человеческой деятельности, но и точные науки, например, математику и физику (см., напр.: [2]).

Для более детального понимания, что же представляет собой лингвистический поворот, рассмотрим идеи некоторых его представите- 
лей, приведенные в упомянутом сборнике работ под редакцией Р. Рорти. На наш взгляд, особый интерес вызывают такие мыслители как Карнап, Бергман, Райл и Виздом, представляющие самые разнообразные оттенки аналитико-философской традиции.

В своей статье «О характере философских проблем» Р. Карнап пытается доказать, что не следует искать философские проблемы на каком-то ином уровне, по сравнению с проблемами эмпирических наук и предлагает рассмотреть саму науку в качестве объекта исследования, оговаривая, что это рассмотрение возможно только с логической точки зрения. «Философия - это логика науки, т. е. логический анализ понятий, предпосылок, доказательств и теорий знания - это смесь прикладной логики и психологии, а иногда и метафизики» $[4$, с. 54-55].

Если данное положение верно, то целесообразно задать вопрос: «Бессмысленны ли положения логики науки?» Витгенштейн представил тезис о бессмысленности метафизических утверждений и схожести философии и логики науки, и эту его точку зрения развил Венский кружок. Чтобы дать утвердительный ответ на вопрос об осмысленном характере высказываний логики науки и, таким образом, философии, Карнап предлагает рассмотреть два вида значений: коннотативные и формальные.

«Вопросы, относящиеся к значению высказываний, мы называем коннотативными (содержательными). В противоположность им под формальными мы понимаем высказывания, относящиеся только к формальной структуре, т. е. к подбору и виду символов (слов), из которых строится высказывание без ссылки на значение символов и высказываний в целом» $[4$, с. 56$]$.

K формальным высказываниям относятся, например, большинство грамматических правил. По мнению Карнапа, логике науки реально принадлежат именно формальные высказывания. Далее Карнап определяет характер философии как логики науки, обозначив ее теорией формальной структуры языка науки, и вводит понятие логического синтаксиса языка науки.

Под логическим синтаксисом языка понимают систему формальных (не относящихся к значению) правил этого языка, среди которых следует различать:

1. Правила образования языковых выражений (formative rules). В частности, эти правила определяют, как из символов (слов) строятся высказывания.

2. Правила преобразования выражений языка (transformation rules), 
по которым мы из данных высказываний получаем новые высказывания.

Карнап вводит понятие синтаксиса, расширяя его, по сравнению с терминологией, принятой в лингвистике. В качестве примера, возьмем «математику Гильберта, которая рассматривает символы и формулы математики без ссылки на значение. Эта математика и является логическим синтаксисом языка» [4, с.57]. Согласно Карнапу, формальными можно сделать и сами логические выводы, т. к. формальный вопрос основывается на правилах преобразования языка, т. е. сводится к синтаксису языка.

Представляет определенный интерес попытка Карнапа уточнить идущее от Канта деление высказываний (суждений) на аналитические и синтетические. Карнап дает следующие определения:

1. Аналитические высказывания - это такие высказывания, которые истинны в любом возможном случае.

2. Синтетические высказывания являются истинными только в определенных случаях.

3. Противоречивые высказывания ложны в любом возможном случае.

По мнению Карнапа, любой вопрос логики науки относится к вопросам логического анализа языка, а такого рода вопросы всегда могут быть сформулированы формальным образом. Сведение к формальному языку делает возможным рассмотрение философских проблем математики, делая их вопросами синтаксиса математического языка, физики, биологии, психологии и др. наук. Карнап утверждает, что задачи философии науки могут быть решены лишь в сотрудничестве между логиками и эмпирическими исследователями.

В своей статье «Логический позитивизм, язык и реконструкция метафизики» Г. Бергман также обращается к лингвистическому повороту в философии, рассматривая некоторые типичные признаки, характерные для этого направления.

По мнению Бергмана, хотя обращение к языку не ново (эпистемология, метафизика), лингвистический поворот в собственном смысле инициировали Рассел, Мур и Витгенштейн. Бергман рассматривает этих философов (а также близких им представителей логического позитивизма) не как философов посредством языка, так как они по-но- 
вому начали использовать язык, который уже не являлся лишь инструментом научных теорий. Так, Бергман подчеркивает, что члены Венского кружка не изобретали новых вопросов. Их вклад - это новый метод в подходах к решению старьх проблем.

«Лингвистический поворот возник из понимания того, что отношения между языком и философией намного ближе, чем между языком и другой дисциплиной» $[3$, с. 64$]$.

Бергман предлагает ввести понятие логической формы, так как предложения, имеющие только грамматическую форму, могут казаться одинаковыми, хотя повествуют о разных вещах. Бергман склоняется к ведению идеального языка, и объясняет, каким должен быть его синтаксис. «Синтаксис имеет дело только со свойствами самих знаков. $<\ldots>$ Идеальный язык - это интерпретированная синтаксическая схема» $[3$, с. 66-67].

Предвидя очевидную критику нового метода, Бергман утверждает, что идеальный язык не порождает регресса при решении философских проблем, настаивая на том, что этот метод наиболее близок к реализации старого идеала философии.

Возможно существование множества идеальных языков. «Идеальный язык содержит имена собственные, т. е. то, к чему они относятся, являясь примером чувственных данных. «Дерево», «камень», в широком смысле сами по себе являются определенными предикатами, но субъекты этих предикатов не относятся к конкретным деревьям и камням» [3, с.69]. Определения же, по Бергману, есть не что иное как лингвистические конструкции.

Г. Райл в работе «Выражения, являющиеся систематическими заблуждениями» задает вопрос: «Можно ли путем философствования проанализировать и прояснить идеи, высказанные простым человеком, ученым или художником?» Он утверждает, что выражения, имеющие место в обычной речи, оказываются заблуждениями, это не значит, что они ложные или бессмысленные, но, употребляя их, человек не совсем точно выражает то, что он хотел бы сказать. Под словом «систематически» Райл имеет в виду то обстоятельство, что все выражения данной грамматической формы будут заблуждениями в определенных случаях и по определенным причинам. Подробнее понять его теорию помогут примеры.

«Рассмотрим отрицательное экзистенциальное утверждение: «Сатана существует» или «единороги не существуют». Если Сатана не существует, то не может быть и утверждения о нем, как например, «я хочу спать» обо мне. Некоторые философы высказывают мнение, что 
это утверждение о чем-то описанном как «идея Сатаны», некоторые, о какой-то неактуализированной сущности по имени Сатана. Обе теории пытаются показать, что что-то должно быть, хотя и не существовать. Но так как мы говорим, что круглые квадраты не существуют, такой вид интерпретации отрицательных существований можно отнести либо к классу имеющихся объектов либо к идеям, но тут возникнут противоречия» $[8$, с. 87].

Поэтому такого рода утверждения нуждаются в совершенно ином методе анализа. «Хищные коровы не существуют», означает: «Ни одна корова не является хищником», или «ни один хищный зверь не является коровой», или «нет ничего, что могло быть и коровой и хищником». То есть, высказывание «коровы-хищники не существуют» - это систематическое заблуждение, а перефразированные высказывания уже таковыми не являются.

«В таких квазионтологических утверждениях грамматическое слово или фраза - субъект начинает обозначать или относиться к чемуто, к чему относится квази-онтологический предикат.

«Сатана не существует» по грамматической форме совпадает с выражением «Капоне не философ», но Сатана - это не имя собственное, и нет никого по имени Сатана, и кто был бы носителем зла» [8, с. 90].

Размышляя об универсалиях, Райл также причисляет их к систематическим заблуждениям, утверждая, что говорить «Непунктуальность осудительна» неправильно, т. к. получается, что непунктуальность должна себя стыдиться, но, говоря так, мы имеем в виду человека. Правильно было бы сказать: «Тот, кто непунктуален, заслуживает осуждения других людей». Конечно, если обычный человек произносит предложение, типа «Добродетель-это награда», это не будет философской ошибкой. Для него наилучший способ объяснить что-то - это краткий способ. Но философы, обобщающие и дифференцирующие высказывания, не должны допускать таких заблуждений. Согласно Райлу, это и есть настоящий философский анализ.

В статье «Философские дилеммы» Дж. Виздом предлагает философам с осторожностью употреблять слово «знать», т.к. мы часто используем его в предложениях чувственного опыта. Согласно Виздому, говоря о материальных объектах, неверно утверждать, «я знаю, что на столе сыр», т.к. наш опыт подсказывает нам, что это может быть и не сыр, (например, нечто похожее на сыр в музее мадам Тюссо), т. е. правильно будет сказать «Возможно на столе сыр, но я могу ошибаться».

Отсюда вытекают три проблемы. 
1. Категориальная (мы должны говорить не о сыре, а о наборе чувственных данных).

2. Проблема знания (нельзя говорить, «я знаю, что ...», надо говорить, «весьма вероятно, что ...»).

3. Проблема оправдания (эмпирические заключения часто бывают реально не подтверждены).

Употребление слова «Знать» в обычном смысле не означает настоящее знание. Даже в предложении «Я знаю, что солнце встанет завтра» мы употребляем его, опираясь на наши предыдущие наблюдения.

Но совершенно иначе мы обходимся со словом «знать» в предложениях «Я испытываю боль» или «Я слышу шум», т. е. предложениях внутренних ощущений. Вряд ли осмысленным будет утверждение: «Он говорит, что испытывает боль, но возможно он ошибается».

«Все вышеперечисленные ошибки происходят в языке не из-за беспорядка, царящего в нем, а потому, что они полезны в какой-то мере. И в связи с этим, философы будут постоянно пытаться говорить о том, о чем невозможно сказать» $[10$, с. 109, 110].

Попытавшись дать оценку лингвистическому повороту как явлению в аналитической философии, явлению «единому в своем многообразии», можно заключить, что не существует единых определяющих черт, характеризующих аналитическое движение во всех его фазах. Из всего вышесказанного очевидно огромное значение лингвистического поворота, поставившего перед собой две основные задачи:

- критическую - задачу анализа и разрешения концептуальных споров и недоразумений;

- дополняющую - уделение большего внимания процессу употребления слов или грамматике и логике языка.

Поскольку из вышесказанного следует, что не существует единой схемы правильного употребления слов, это поле деятельности остается открытым для новых исследований. «Каждое поколение должно заново трудиться, ведь достигнув вершины и сообщив, что они видят свет, они все же знают, что тучи собираются за горизонтом» [6, с. 30].

\section{1 Литература}

[1] Уорф Б. Отношение норм поведения и мышления к языку // Новое в лингвистике. Вып. 1. - М.: Иностр. лит., 1960 - С. 135-168. 
[2] Шрамко Я.В. Возникновение, становление и развитие аналитической философии // Актуальні проблеми духовності. - Вип.6. Кривий Ріг: КДПУ, 2005.- С. 185-196.

[3] Bergmann G. Logical positivism, language and the reconstruction of metaphysics // Rorty R. (ed.) The Linguistic Turn: Essays in Philosophical Method. - Chicago: The University of Chicago Press, 1992. - P. 63-71.

[4] Carnap R. On the character of Philosophical Problems // Richard Rorty (ed.) The Linguistic Turn: Essays in Philosophical Method.Chicago: The University of Chicago Press, 1992. - P. 54-62.

[5] Føllesdal D. Analytic philosophy: what is it and why should one engage in it? // Glock H.-J. (ed.) The Rise of Analytic Philosophy. Blackwell Publishers, 1997. - P. 1-16.

[6] Hacker P.M.S. Analytic philosophy: what, whence, and whiter? // Biletzki A. and A. Matar (eds.) The Story of Analytic Philosophy. London and New York: Routledge, 1998. - P. 3-34.

[7] Rorty R. Introduction. Metaphilosophical difficulties of linguistic philosophy // Rorty R. (ed.) The Linguistic Turn: Essays in Philosophical Method. - Chicago: The University of Chicago Press, 1992. - P. 1-37.

[8] Ryle G. Systematically misleading expressions // Richard Rorty (ed.) The Linguistic Turn: Essays in Philosophical Method. - Chicago: The University of Chicago Press, 1992. - P. 85-100.

[9] Waismann F. Was ist logische Analyse? // Erkenntnis. - 1940.VIII. - P. 265-289.

[10] Wisdom J. Philosophical perplexity // Richard Rorty (ed.) The Linguistic Turn: Essays in Philosophical Method. - Chicago: The University of Chicago Press, 1992. - P. 101-110. 